\title{
Prospect of Utilization of Solar Energy in SWCC Existing MED Desalination Satellite Plants
}

\author{
Ahmed Saeed Al-Ghamdi", Amro Mohammed Mahmoud, Khalid Bamardouf \\ Thermal Department, Desalination Technologies Research Institute (DTRI-SWCC), Jubail, Saudi Arabia \\ Email address: \\ AAl-Ghamdi34accb@swcc.gov.sa (A. S.Al-Ghamdi) \\ *Corresponding author \\ To cite this article: \\ Ahmed Saeed Al-Ghamdi, Amro Mohammed Mahmoud, Khalid Bamardouf. Prospect of Utilization of Solar Energy in SWCC Existing \\ MED Desalination Satellite Plants. International Journal of Mechanical Engineering and Applications. Vol. 8, No. 3, 2020, pp. 88-94. \\ doi: $10.11648 /$ j.ijmea.20200803.12
}

Received: July 13, 2020; Accepted: July 27, 2020; Published: August 31, 2020

\begin{abstract}
The shortage of drinking water source limits the socio-economic development of many areas of the world. Saudi Arabia has very limited resources in fresh water source and around 40 to 50\% of portable water in Saudi Arabia is produced by desalination technology which depends on using fossil energy. The high cost of the water and electricity production reflects depleting the Oil resources of the country which is nonrenewable, solar energy would be a good alternative since Saudi Arabia has abundant free solar energy. This study investigates the feasibility of using concentrated solar power system (CSP) for thermal desalination. The study is conducted for CSP coupled with multi effect desalination with thermal vapor compressor (MED-TVC) existed in western province Saudi Arabia in five locations with various DNI, for two cases, without storage and with 16 hours storage. The total saving from coupling solar collectors to all five plants shows around 20.45 million $\$$ per year. Using of solar energy can reduce carbon dioxide emission to the environment by 420 thousands ton per year for all selected plants.
\end{abstract}

Keywords: MED-TVC, Solar, Desalination, Cost of Water (LCOW)

\section{Introduction}

Fresh water demand is persistently increasing as populations around the world keep growing and as existing fresh water reserves keep declining due to high consumption and pollution [1]. The worldwide capacity of desalination using renewable energy is less than $1 \%$ of that of conventional desalination due to high capital and maintenance costs associated with using renewable energy Therefore, further techno economic evaluations are needed and are important steps to select the promising configuration before construction phase.

$97 \%$ of the earth's water is available is salty water in the oceans and sea while only $3 \%$ remained is fresh water. About $70 \%$ of the fresh water is frozen in the earth poles and the other $30 \%$ is ground water Rivers, which used for drinking water [2]. Therefore this limited resources of fresh water is not enough to fulfill human requirement as drinking, industrial and agriculture use. Desalination can play an important solution of the scarcity of fresh water.
Two main techniques are used in desalination: by evaporation or by using of a semi-permeable membrane to separate fresh water from a concentrate. Historically, seawater desalination has been the most expensive way to produce drinking water at the commercial scale because of the high capital and energy costs [3]. Fuel cost is major component of water unit cost almost $40-50 \%$ of the water total cost. Many research works have been conducted to reduce the fuel cost by increasing efficiency and change fuel sources.

Solar energy considered as attractive source of renewable clean energy, which does not contribute to global warming. Attention has been directed towards improving the conversion efficiency of solar energy systems, in other hand desalination technologies are highly intense power consumption industry. Optimization coupling between desalination and solar system is highly attractive to enhance the economics of desalination with have reliable and renewable source of energy. Solar desalination is in particular attractive and promising in 
high solar radiation intensity countries such as KSA and Gulf countries in general. There are essentially two widely known methods to combine solar and desalination systems. The solar collection sub-system is used either to collect heat using solar collectors and supply it via a heat exchanger to a thermal desalination process or convert heat to electricity using photovoltaic cells to drive pressure driven technology; membrane desalination process (Reverse osmosis).

\section{Materials and Methods}

This Project will focus on analyze the operation data of the existing MED (Multi Effect Desalination) units located in red sea coastal of Saudi Arabia, based on: solar radiation data Figure 1 shows the solar intensity in the kingdom and plants locations.

A techno-economic analysis based on mass and energy balances for the main components of the solar desalination system and cost estimation giving the total cost of water.

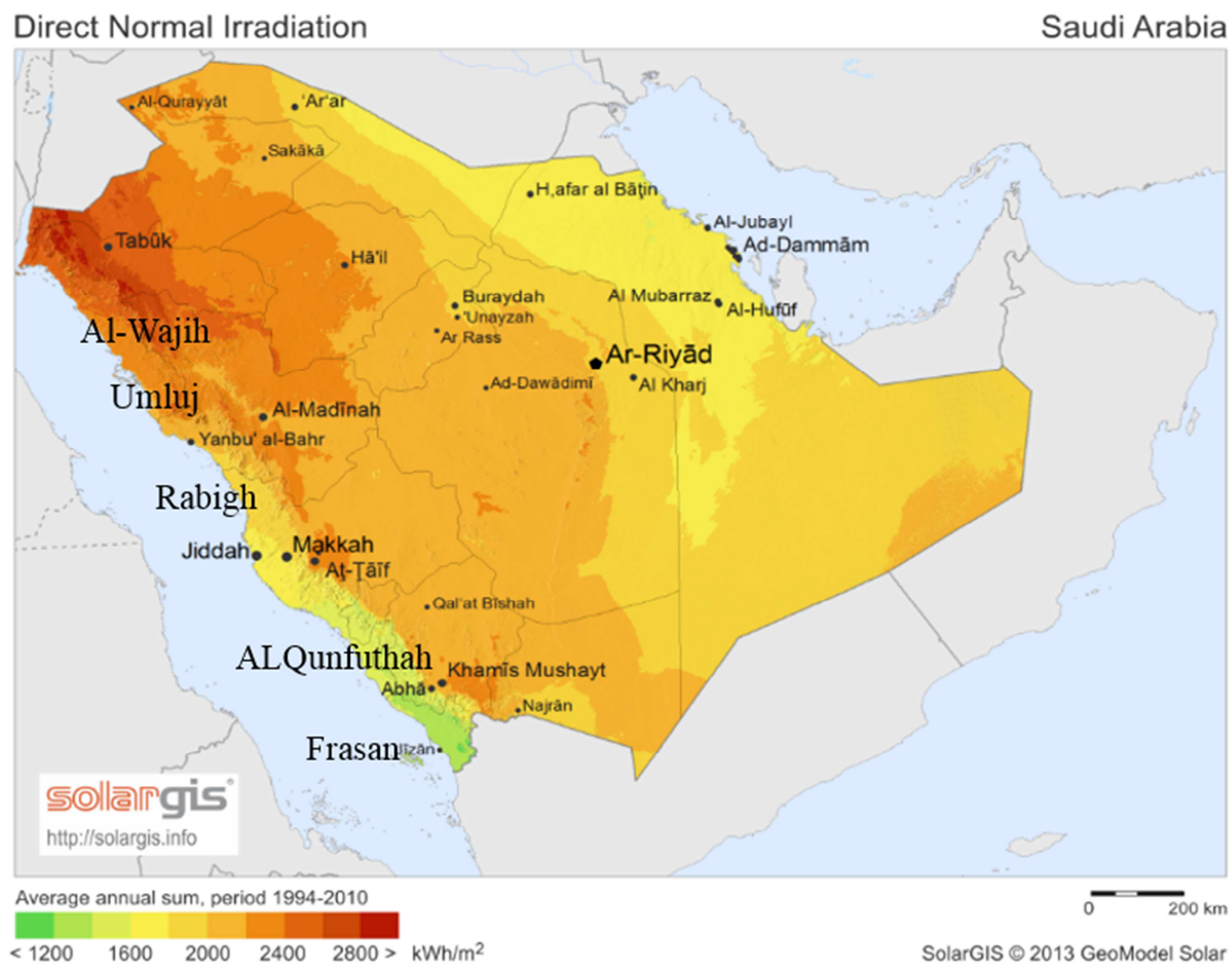

Figure 1. Solar radiation in Saudi Arabia.

The selected locations solar data is shown in table 1 [5].

Table 1. Solar radiation at different location.

\begin{tabular}{ll}
\hline Location & Radiation $\mathbf{k W h} / \mathbf{m}^{2} / \mathbf{d a y}$ \\
\hline Al-Wajih & 2450 \\
Umluj & 2300 \\
Rabigh & 1900 \\
AlQunfuthah & 1600 \\
Frasan & 1485 \\
\hline
\end{tabular}

MED-TVC desalination plants have different production capacity varied from ( 8000 to $18000 \mathrm{~m}^{3} /$ day) and different performance ratio (8-10) detail heat and mass balance was carried out based on actual operational data to estimate the required energy to drive the unit all over the year. Estimation of required solar field was estimated using System Advisor Model (SAM) developed by the National Renewable Energy Laboratory (NREL) USA. An economic model developed and implemented on Excel tool by DTRI thermal team was used to evaluate the cost of water. Considering different thermal storage time ( 0 hour, and 16 hour's storage).

\subsection{Research Objectives}

The principle objective of the project is to conduct a feasibility study on the utilization of solar energy to thermal desalination plants in Saudi Arabia. The specific objectives 
can be expressed as:

To develop the appropriate design, configuration and operating conditions of solar assisted thermal desalination systems located in the Western Coast of Saudi Arabia.

To conduct technical and cost studies of the solar desalination system with and without storage for a one year period.
Economic benefits of such integration.

\subsection{Research Methodology}

The methodology of this thesis can be describe as shown in Figure 2.

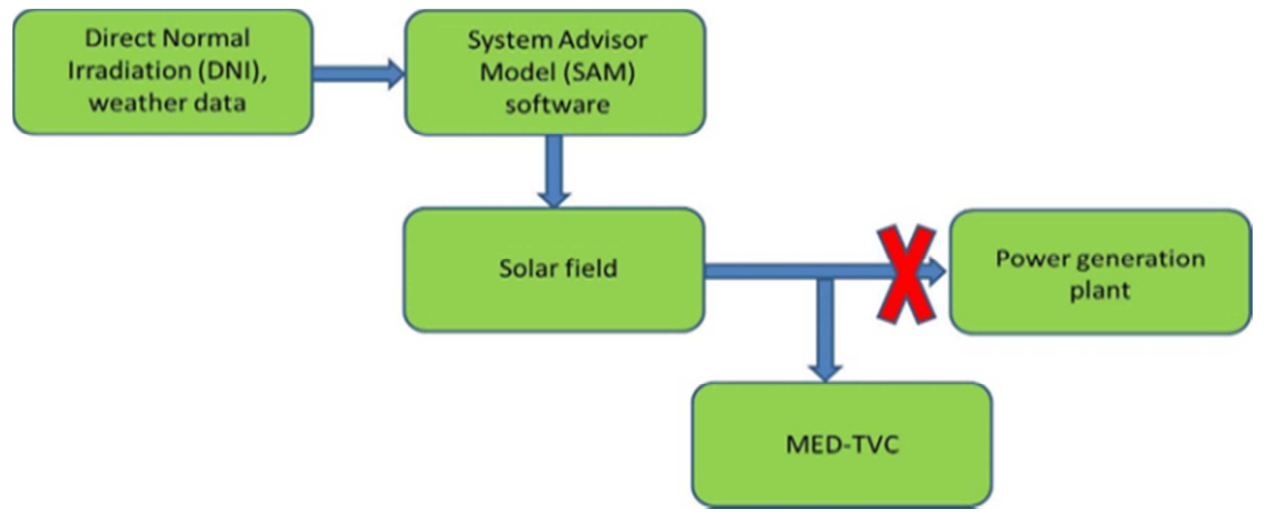

Figure 2. A simplified diagram for the project methodology.

SAM advisor model which is developed at the National Renewable Energy Laboratory (NREL), usually used to simulate solar field assisted power plants that simulate the CSP system by using solar data however, the solar field and related output would be extracted from SAM used as input to the generated in house excel file to calculate the specific water production cost. The procedure of calculation is shown in figure 2 .

Table 2. Existed MED-TVC plants criteria.

\begin{tabular}{llll}
\hline & Production $\left(\mathbf{m}^{\mathbf{3}} / \mathbf{d a y}\right)$ & PR & Availability \\
\hline Al-Wajih & 8400 & 8.4 & 98 \\
Umluj & 12100 & 9 & 97 \\
Rabigh & 17600 & 9.4 & 98 \\
AlQunfuthah & 7600 & 10 & 95 \\
Frasan & 7400 & 7.9 & 98 \\
\hline
\end{tabular}

The analysis is based on the conservation of mass and energy principles with technical specifications of the various components of the combined plant. Up to date prices for the various systems and fuels needed in the economic analysis is considered in order to have a reliable results. Theoretical models based on the first law of thermodynamic for solar collector assisted of MED-TVC will be developed. The solar collector will be simulated and designed by using System Advisor module (SAM).

Several scenarios characterized by various configurations of solar collectors and desalination technologies and options on the use of storage system shall be considered and analyzed in the study. The comprehensive study will cover the following configurations:

Hybrid system Linear Fresnel assisted MED-TVC with back up fossil fuel.

Hybrid system Linear Fresnel assisted MED-TVC with thermal storage 16 hours.

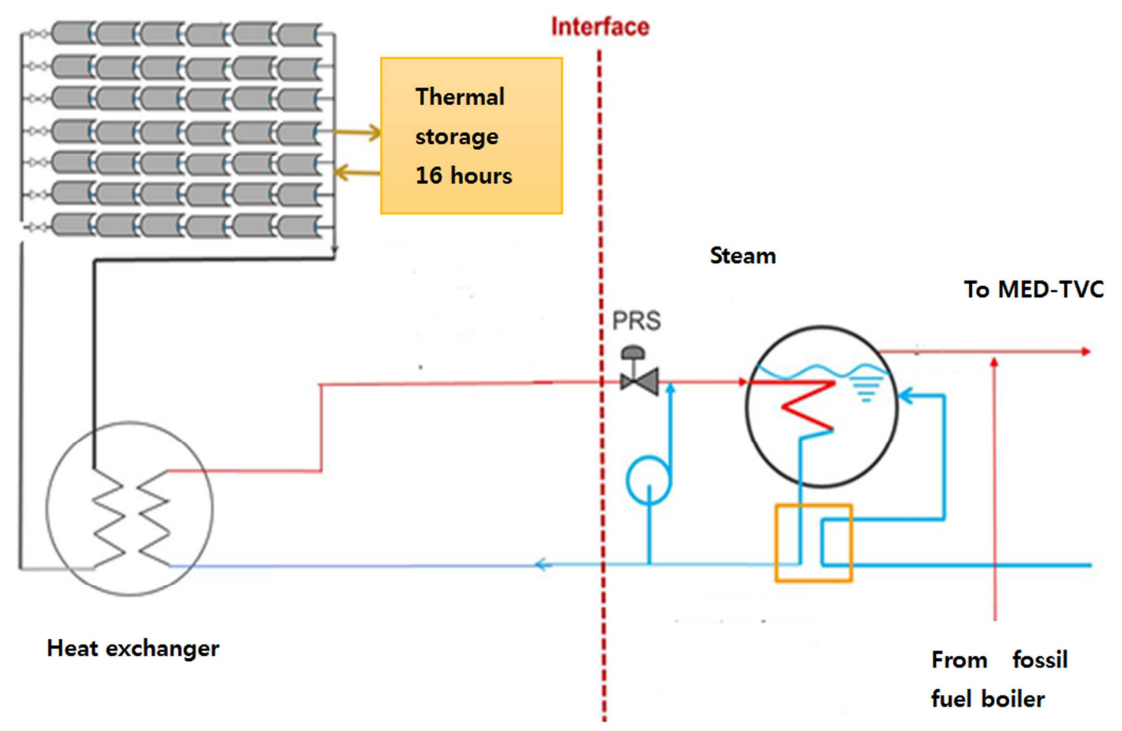

Figure 3. Configuration of CSP coupled with MED-TVC. 
The proposed system can be described as in Figure 3, which shown the hybridization of the solar system (power source) and the steam transformer which is used to produce the steam which drive the MED TVD plant.

\subsection{Mathematical Model}

An Excel program is used to evaluate the cost of water; it is linked between MED-TVC model and CSP model. Thermal energy required to operate MED-TVC plant calculated as in Equation 1.

$$
Q s=\frac{D T}{P R} *(H s i-H s o)
$$

Then by using (SAM) the solar field area calculated based on required energy, form solar field area CAPEX of solar field calculated based on the values on table 3 . he contingency and engineering, procurement and construction management cost (EPC) are added to the capital cost as percentage of total cost as 7\% contingency and 11\% EPC cost. The capital cost of solar system calculated from following equations.

Table 3. Capital cost for CSP system based to SAM program.

\begin{tabular}{lll}
\hline & LFR (steam HTF) & LFR (molten salt HTF) \\
\hline Site improvement & $20 \$ / \mathrm{m}^{2}$ & $20 \$ / \mathrm{m}^{2}$ \\
Solar field & $150 \$ / \mathrm{m}^{2}$ & $150 \$ / \mathrm{m}^{2}$ \\
HTF system & $33 \$ / \mathrm{m}^{2}$ & $47 \$ / \mathrm{m}^{2}$ \\
Storage & $32 \$ / \mathrm{kWht}$ & $32 \$ / \mathrm{kWht}$ \\
\hline
\end{tabular}

The capital cost of MED-TVC can be calculated as unit cost equal $1542 \$ / \mathrm{m}^{3} /$ day [6], and operation cost of MEDTVC equal $0.18 \$ / \mathrm{m}^{3} /$ day including pumping cost [7]. Table 4 used to calculate the OPEX of solar field.

Table 4. Operation cost of solar field [8].

\begin{tabular}{ll}
\hline & LFR \\
\hline Operation cost of solar field & $11.2 \$ / \mathrm{m}^{2}$ \\
Operation cost of storage & $70 \$ / \mathrm{MWh} /$ year \\
\hline
\end{tabular}

Back up fossil fuel calculated from the balance energy required as number of barrels, then multiply by the oil price from 10 to $100 \$ / \mathrm{bbl}$ to calculate specific fuel cost $\$ / \mathrm{m}^{3}$. Cost of water calculated from all previse information and calculation by the following method:

Find total capital investment by summation all capital cost of integrated system

$$
\begin{gathered}
\text { total CAPEX }=\text { CAPEX of solar }+ \text { CAPEX of MED + } \\
\text { CAPEX of boiler }
\end{gathered}
$$

The LCOW calculated by using the following equation which depend of economic methods. [9]

$$
L C O W=\frac{C r f * C A P E X+O P E X+B a c k u p \text { fuel cost }}{\text { water production }}
$$

Where (CRF) The capital recovery factor is generally used to find out the uniform annual amount 'CAPEX' of a uniform series from the known present worth at a given interest rate
' $i$ ' per interest period (n) [10].

$$
\operatorname{Crf}=\left(\frac{\mathrm{z}(1+\mathrm{z})^{\mathrm{n}}}{(1+\mathrm{z})^{\mathrm{n}}-1}\right)+\mathrm{k}
$$

Where:

$\mathrm{Z}$ is discount rate assumed as 0.05

$\mathrm{N}$ is amortization period per year assumed 20 years

$\mathrm{K}$ is yearly insurance assumed 0.01

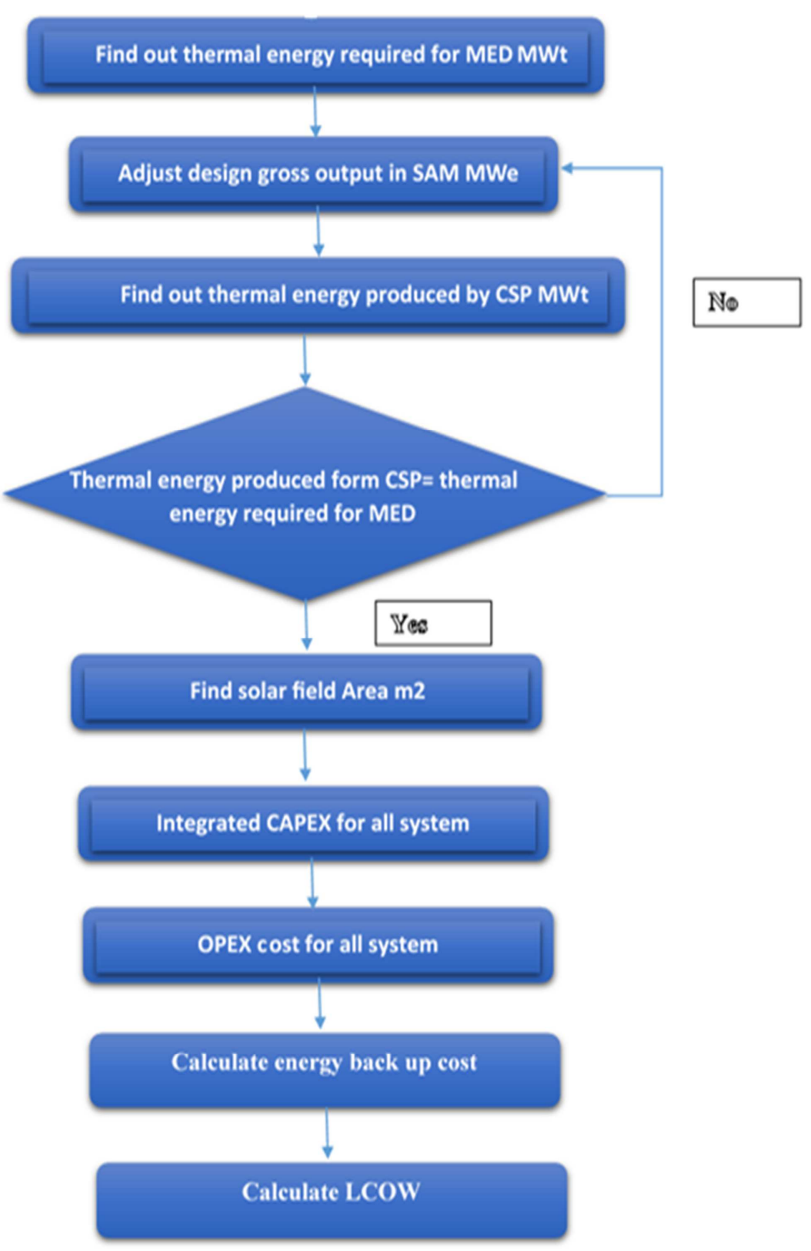

Figure 4. Description of the general calculation procedure of project.

\section{Results and Discussion}

A techno economic analysis was performed for MED-TVC desalination plant based of Average plant production, performance ratio and Availability extracted from actual data. Figure 5 shows the variation of water cost with oil price for each plant simulated as operated 8 hours by using Linear Fresnel and the rest of the day by back up fossil fuel. Then compared with conventional plant operated by fossil fuel only, which presented as dotted line in the figure this would give a clear criteria for the economic benefits via different oil prices.

As expected the best economic benefits when the solar radiation is high with high performance MED; Frasan shows was found as the worst unit for coupling solar with MED- 
TVC desalination unit that since it has low DNI and low performance (efficiency) plant. While Umluj was the best option for such configuration. Detail analysis is shown in figures 5 and 6 for different storage. However All the plants are economically feasible almost at oil price $25 \$ / \mathrm{bbl}$. except Frasan plant at $45 \$ / \mathrm{bbl}$. which present the worst case.

Table 5 summarize the main results at international oil price $(60 \$ / \mathrm{bbl}$.$) , it is shows the feasibility, water cost and$ saving for each plant when coupled with LFR without storage.

Figure 6 shows variation of water cost with oil price for individual plants simulated as operated 24 hours by using LFR. MED-TVC plant, using of LFR for 16 hours shows give water cost stability and at high oil price more economically feasible than conventional MED-TVC and LFR assisted MED-TVC without storage. Additionally in this case the plant performance more effective in the plant because effecting in the solar collector area the breakeven cost start at $30 \$ /$ bbl. for the best plant Umluj and shows around $50 \$ / \mathrm{bbl}$. for worst plant which is Farasn. The cost of water and saving \$/year shown better when using 16 hours storage comparing to LFR without storage.

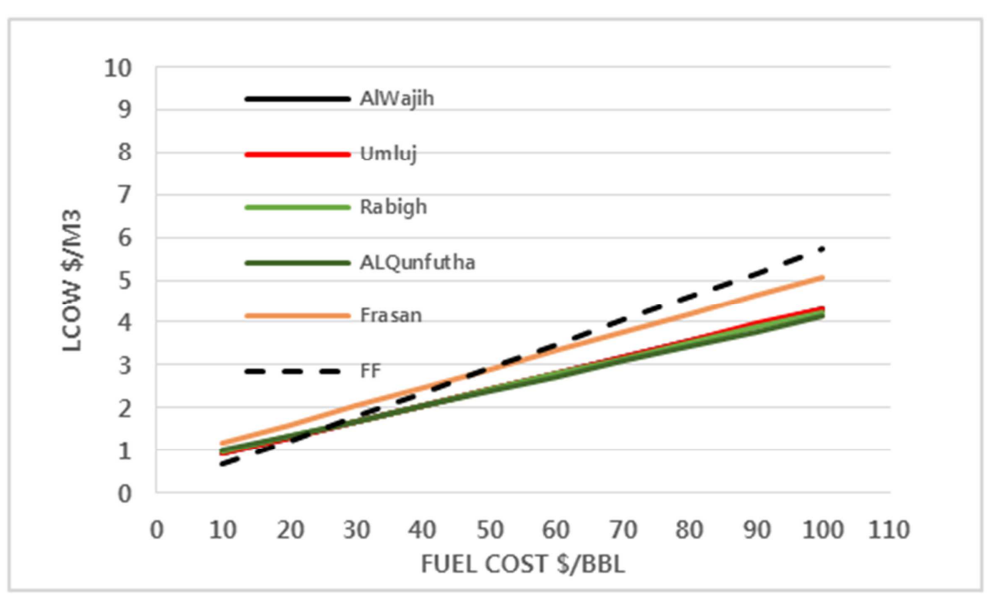

Figure 5. Variation of water cost without storage.

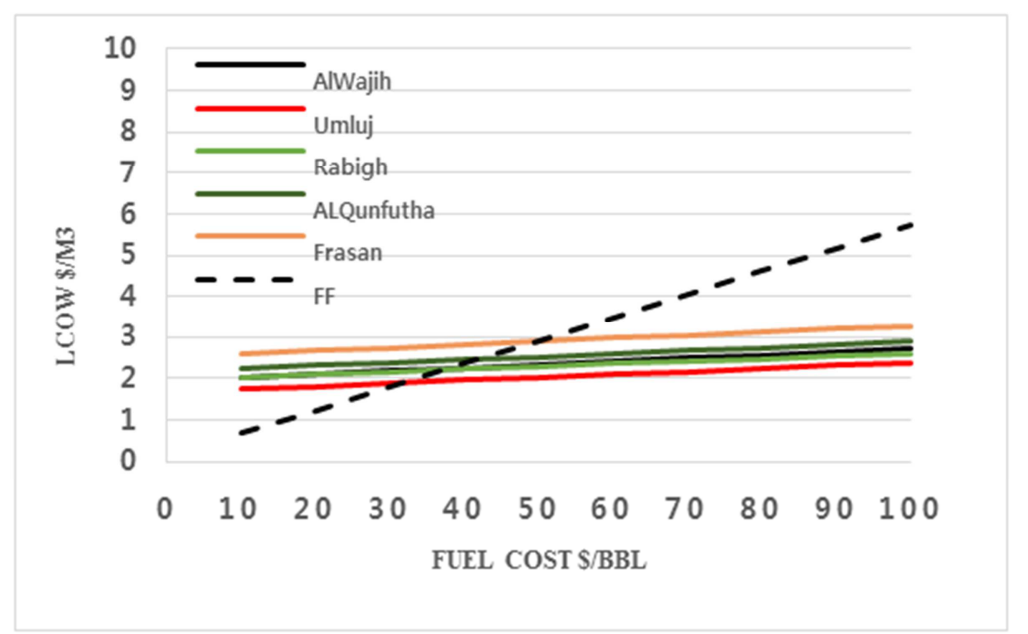

Figure 6. Water cost vs oil price 16 hours storage.

Table 5. Simulation results for case LFR-MEDTVC without storage.

\begin{tabular}{|c|c|c|c|c|c|c|}
\hline @oil price $60 \$ / \mathrm{bbl}$. CSP+MEDTVC (0hr storage) & Conventional MED-TVC & Al-Wajih & Umluj & Rabigh & AlQunfuthah & Frasan \\
\hline Unit production $\$ / \mathrm{m}^{3}$ & 3.48 & 2.81 & 2.82 & 2.79 & 2.73 & 3.33 \\
\hline Gain output ratio (Kg product $/ \mathrm{kg} /$ steam) & 9 & 8.4 & 9 & 9.4 & 10 & 7.9 \\
\hline TBT & 65 & 65 & 65 & 65 & 65 & 65 \\
\hline Motive Steam pressure & 8 & 8 & 8 & 8 & 8 & 8 \\
\hline Solar field area & 0 & 49305 & 65741 & 106829 & 54362 & 57523 \\
\hline Solar operational hours & 0 & 8 & 8 & 8 & 8 & 8 \\
\hline Plant production & 9000 & 8400 & 12100 & 17600 & 7600 & 7400 \\
\hline Amortization period year & 25 & 25 & 25 & 25 & 25 & 25 \\
\hline Operation cost $(\mathrm{MED}+\mathrm{CSP}) \$ / \mathrm{m}^{2}$ & 0.27 & 0.45 & 0.44 & 0.45 & 0.51 & 0.49 \\
\hline Carbon Dioxide Reduction T/Y & 0 & 27 & 34 & 53 & 21 & 25 \\
\hline Total Saving Million (\$/Y) & 0 & 2 & 2.9 & 4.4 & 2.08 & 0.41 \\
\hline
\end{tabular}


Table 6. Simulation results for case LFR-MEDTVC with 16 hours storage.

\begin{tabular}{|c|c|c|c|c|c|c|}
\hline @oil price 60\$/bbl. CSP+MEDTVC (16hr storage) & Conventional MED-TVC & Al-Wajih & Umluj & Rabigh & AlQunfuthah & Frasan \\
\hline Unit production $\$ / \mathrm{m}^{3}$ & 3.48 & 2.41 & 2.1 & 2.35 & 2.6 & 2.97 \\
\hline Gain output ratio (Kg product $/ \mathrm{kg} / \mathrm{steam})$ & 9 & 8.4 & 9 & 9.4 & 10 & 7.9 \\
\hline TBT & 65 & 65 & 65 & 65 & 65 & 65 \\
\hline Motive Steam pressure & 8 & 8 & 8 & 8 & 8 & 8 \\
\hline Solar field area & 0 & 158021 & 195645 & 346141 & 173256 & 195645 \\
\hline Solar operational hours & 0 & 24 & 24 & 24 & 24 & 24 \\
\hline Plant production & 9000 & 8400 & 12100 & 17600 & 7600 & 7400 \\
\hline Amortization period year & 25 & 25 & 25 & 25 & 25 & 25 \\
\hline Operation cost $(\mathrm{MED}+\mathrm{CSP}) \$ / \mathrm{m}^{2}$ & 0.27 & 0.86 & 0.77 & 0.88 & 0.98 & 1.09 \\
\hline Carbon Dioxide Reduction T/Y & 0 & 70 & 93 & 136 & 54 & 67 \\
\hline Total Saving Million (\$/Y) & 0 & 3.3 & 6.09 & 7.25 & 2.44 & 1.37 \\
\hline
\end{tabular}

\section{Conclusions}

A techno economic analysis of combination between CSP and MED-TVC was carried out for five existed MED-TVC plants located at western region of Saudi Arabia (AL-Wajih, Umluj, Rabigh, AL-Qunfuthah and Frasan). Energy consumption of MED-TVC calculated by the information from each plant based on plant capacity, performance ratio, Temperatures and pressures. Based of energy requirement, simulation was conducted to couple these plants with Linear Fresnel collector to provide a thermal energy required to run such units. System advisor model (SAM) was used to simulate leaner Fresnel with different thermal storage capacity ( 0 and 16 hours storage) the coupled systems simulated by using Excel program, all cases compared with conventional MED-TVC (running by fossil fuel) as a reference to find out the breakeven cost with different fossil fuel price. The main issue in these plants is fuel consumption which is too high $\left(14.3 \mathrm{KW} / \mathrm{m}^{3}\right)$.

Using of LFR coupled with MED TVC is feasible average of breakeven cost for all plants is $25 \$ / b b l$. for zero hour storage case except Frasan plant at 50\$/bbl. For 16 hours storage the difference is appear in breakeven cost between each plants. The lower breakeven cost shows in Umluj plant where higher performance ratio and very high DNI breakeven cost $32 \$ /$ bbl. compare to Frasan which has low performance and low DNI it shows the higher breakeven cost $50 \$ / \mathrm{bbl}$. The results shows also using of 16 hours storage is more feasibility than other cases when the LCOW calculated based on unsubsidized fuel cost $(60 \$ / \mathrm{bbl}$.), and using zero $\mathrm{hr}$. storage is more feasible when fuel cost from 25 to $40 \$ / b b l$. According to the results including fuel transportation cost the using of 16 hours storage is more feasible than other case in all fuel cost from 35 to $100 \$ / b b l$. the total saving from coupling solar collectors to all five plants shows around 20.45 million \$ per year. Also the main side effect of using fossil fuel is pollution the results shows that using of solar energy can be reduce of carbon dioxide emission to the environment by 420 thousands ton per year for all selected plants.

Next step a validation would be a test for different solar collector and select the most efficient and cost effective to be coupled with actual plant in selected SWCC plant. The project is in progress. Such technology coupled with high efficient thermal MED would be a breakthrough in thermal desalination.

\section{Nomenclatures}

BBL: barrel of oil

CAPEX: capital cost

CSP: concentrated solar power

DNI: direct normal irradiation

DT: total distillate mass flow rate $\mathrm{kg} / \mathrm{s}$

Ds: motive steam flow rate $\mathrm{kg} / \mathrm{s}$

EPC: engineering procurement and management construction cost

FT: total feed flow rate $\mathrm{kg} / \mathrm{s}$

$\mathrm{K}$ : yearly insurance

LCOW: levelized cost of water

LFR: linear Fresnel collector

MED-TVC: multi effect desalination unit with thermal vapor compressor

$\mathrm{N}$ : amortization period

OPEX: operation cost

PR: performance ratio

Q: specific heat consumption

\section{References}

[1] Goswami Yogi, Abutayeh mohammad, li Chennan. Solar desalination. Researchgate Jan 2014.

[2] A. M. K. El-Ghonemy. Future sustainable water desalination technologies for the Saudi Arabia: A review. Renewable and Sustainable Energy Reviews 16 (2012) 6566-6597.

[3] li Chennan, Goswami Yogi. Solar assisted sea water desalination: A review. Renewable and Sustainable Energy Reviews. March 2013.

[4] Mahmoud Shatat, Mark Worall, Saffa Riffat. Opportunities for solar water desalination worldwide: Review. Sustainable Cities and Society 9 (2013) 67-80.

[5] https://rratlas.energy.gov.sa/.

[6] Nuri Eshoul, Abdulrahman Almutairi, Rasaq Lamidi 3, Hamad Alhajeri and Abdulrahman Alenezi, Energetic, Exergetic, and Economic Analysis of MED-TVC Water Desalination Plant with and without Preheating, Water 2018, 10, 305; doi: 10.3390/w10030305. 
[7] Narmine H. Aly, Evaluation of Water Cost from Seawater Desalination in Dual- Purpose Plants for Potable Water Production and Electricity, Fourth International Water Technology Conference IWTC 99, Alexandria, Egypt.

[8] Tobias Hirsch, Christian Sattler, Heike Glade, Andrea Ghermandi. Techno-economic analysis of combined concentrating solar power and desalination plant configurations in Occupied lands and Jordan. desalination water treatment. 2012.
[9] Osman Ahmed Hamed, Hiroshi Kosaka, Khalid H. Bamardouf, Khalid Al-Shail, Ahmed S. Al-Ghamdi, Concentrating solar power for seawater thermal desalination, Desalination 396 (2016) 70-78.

[10] P. Palenzuela, G. Zaragoza, D. C. Alarcón-Padilla, J. Blanco, Large-scale solar desalination by combination with CSP: techno-economic analysis of different options for the Mediterranean Sea and the Arabian Gulf, Desalination 366 (2015) 130-138. 